\section{Verdoppelung der Diabeteshäufigkeit bis 2020}

Die EURODIAB-Studiengruppe um Chris Patterson legt einen Bericht über die Häufigkeit des Typ-1-Diabetes bei Kindern vor. Sollten die aktuellen Trends anhalten, sagen die Wissenschaftler eine Verdoppelung der Fälle von Diabetes Typ 1 in den nächsten zehn Jahren in Europa bei Kindern unter fünf Jahren voraus.

Fin internationales Forscherteam - wertete die Gesundheitsregister von 17 europäischen Staaten aus. In diesen Registern waren für den 15-Jahres-Zeitraum von 1989 bis 2003 insgesamt 29.311 neu aufgetretene Fälle von Typ1-Diabetes vor dem 15. Geburtstag der

Kinder erfasst. Von den 17 nationalen Registern zeigten 15 einen signifikanten jährlichen Anstieg der Inzidenz zwischen 0,6\% und 9,3\%. Die Zahl der neu aufgetretenen Fälle in Europa im Jahr 2005 wurde auf 15.000 geschätzt, wobei $24 \%$ auf die 0 - bis 4 -Jährigen, $35 \%$ auf die

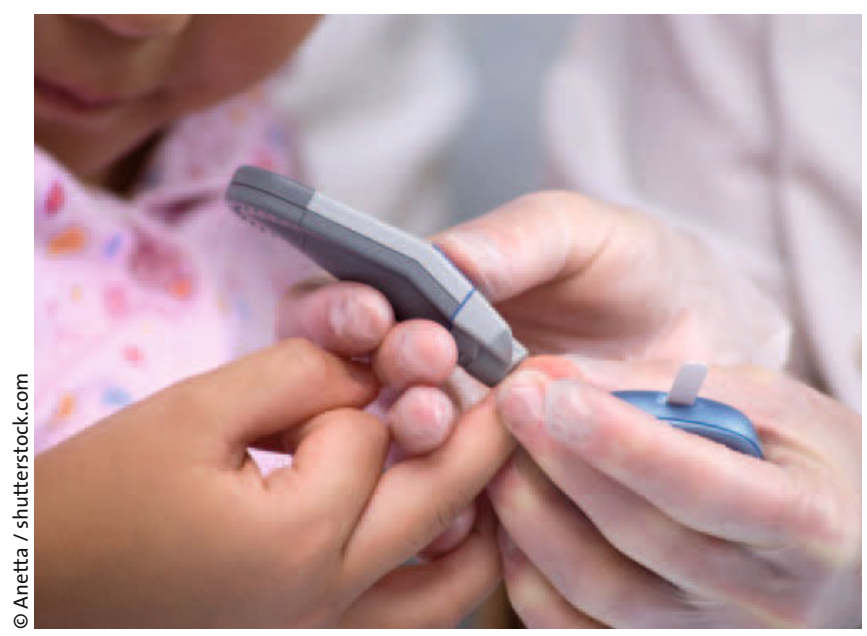

Immer häufiger wird in Zukunft die Blutzuckermessung nötig sein.
5- bis 9-Jährigen und 41\% auf die 10bis 14-Jährigen entfielen. Die Autoren verdeutlichen, dass bei Fortsetzung dieses Trends mit einer Verdoppelung der Fälle vom Typ-1-Diabetes bei den unter 5-Jährigen zwischen 2005 und 2020 zu rechnen ist. Die Wissenschaftler sagen außerdem voraus, dass die Prävalenz bei Kindern unter 15 Jahren um $70 \%$ ansteigen wird, von $94.000 \mathrm{im}$ Jahr 2005 auf 160.000 im Jahr 2020.

Kommentar: Die Zahlen machen deutlich, dass nicht nur Grundlagenforschung erforderlich ist, um die komplexe Ätiologie der Erkrankung zu verstehen. Auch der Stellenwert des kindlichen Diabetes an den Kosten des Gesundheitswesens wird deutlich steigen. Besonders bedenklich stimmt der Hinweis von Dana Dabelea in einem Kommentar derselben Ausgabe des Lancet, dass die Prävalenz des Typ-1-Diabetes bei Kindern in den weniger gut entwickelten Teilen der Welt noch stärker steigen wird.

Dr. Hartmut Koch

Patterson CC et al. EURODIAB Study Group. Incidence trends for childhood type 1 diabetes in Europe during 1989-2003 and predicted new cases 2005-20: a multicentre prospective registration study. Lancet 2009; 373: 2027-33

Kommentar: Systemische Reaktionen im Rahmen eines Pricktests sind zwar selten, aber möglich. Diese aussagekräftige prospektive Studie beziffert das Risiko systemischer Reaktionen bei Pricktestungen auf ca. 1 Promille, wie schon bereits aus kleineren retrospektiven Studien zu vermuten war. Außerdem listet sie auch genauere Risikofaktoren auf, die es dem Kinderarzt ermöglichen, besser auf diese Notfälle vorbereitet zu sein. Ähnlich wie bei Impfungen sind auch Mädchen beim Pricktest eher Kandidaten für vasovagale Reaktionen und Synkopen.

Dr. Ulrich Mutschler

Norrman G et al. Adverse reactions to skin prick testing in children - prevalence and possible risk factors. Pediatr Allergy Immunol 2009; 20: 273-8 